\title{
The Extent of Solubilization of Flurbiprofen and Ketoprofen by Cetyltrimethylammonium Micelles Using Semi-Equilibrium Dialysis
}

\author{
Jimmy D. Roach*, Ibrahim Laswi, Malik Mushannen, Ali Chaari, Mandy Bondaruk \\ Pre-Medical Education Unit, Weill Cornell Medical College-Qatar, Doha, Qatar \\ Email: ^jar2038@qatar-med.cornell.edu
}

How to cite this paper: Roach, J.D., Laswi, I., Mushannen, M., Chaari, A. and Bondaruk, M. (2020) The Extent of Solubilization of Flurbiprofen and Ketoprofen by Cetyltrimethylammonium Micelles Using SemiEquilibrium Dialysis. Advances in Materials Physics and Chemistry, 10, 97-109. https://doi.org/10.4236/ampc.2020.104008

Received: March 29, 2020

Accepted: April 26, 2020

Published: April 29, 2020

Copyright $\odot 2020$ by author(s) and Scientific Research Publishing Inc. This work is licensed under the Creative Commons Attribution International License (CC BY 4.0).

http://creativecommons.org/licenses/by/4.0/

\begin{abstract}
The partitioning of two non-steroidal anti-inflammatory drugs (NSAIDs), flurbiprofen and ketoprofen, into cationic cetyltrimethylammonium micelles was investigated using semi-equilibrium dialysis at $37^{\circ} \mathrm{C}$ in phosphate buffered saline. The micellar-water solubilization equilibrium constants for both NSAIDs, in their deprotonated forms, were observed to decrease linearly with increasing mole fraction of drug in micelles. For flurbiprofen, the solubilization constant in the limit as mole fraction of drug in micelles approaches zero was found to be $11,200\left(c^{\circ}=1 \mathrm{M}\right)$, while for ketoprofen the value was 1950 $\left(c^{\circ}=1 \mathrm{M}\right)$. Using ${ }^{1} \mathrm{H}-\mathrm{NMR}$ and UV spectroscopic techniques, the locus of solubilization for ketoprofen was found to be towards the charged exterior of the micelles, in the Stern layer, whereas flurbiprofen was found to solubilize more in the micellar interior.
\end{abstract}

\section{Keywords}

Flurbiprofen, Ketoprofen, CTAB, Micelle, Solubilization

\section{Introduction}

Non-steroidal anti-inflammatory drugs (NSAIDs) are a classification of medication used primarily for their anti-inflammatory, antipyretic, and analgesic activities. Globally, NSAIDs are the most widely used pharmaceutical drug [1]. The principal mode of action for NSAIDs is inhibition of the cyclooxygenase enzymes, COX-1 and COX-2. Available evidence suggests that the analgesic and anti-inflammatory properties of NSAIDs arise from their inhibition of the COX-2 isoform, while common gastrointestinal side effects associated with their use are 
due to inhibition of COX-1. Recently, certain NSAIDs have also emerged as valuable drugs in the treatment or prevention of breast cancer [2], colorectal cancer [3], bone loss in postmenopausal women [4], and even certain neurodegenerative diseases [5]. Despite their prevalence, many NSAIDs have poor biopharmaceutical properties like low water solubility, rapid metabolism and excretion, and deleterious side effects [6]. Surfactant micelles have been shown to improve these biopharmaceutical properties when used as drug carriers [7], however few studies have investigated the physico-chemical interactions between NSAIDs and surfactants, especially as a function of micellar mole fraction of drug. Such studies are of interest to both the pharmaceutical sciences, because of micellar-based drug delivery systems and the use of surfactant systems as biological membrane mimics, and to the environmental sciences, because of the impact these drugs have on both terrestrial and marine ecosystems, and their potential removal using a surfactant-based remediation technology i.e. micellar-enhanced ultrafiltration (MEUF).

In aqueous solution, surfactant micelles are organized with hydrophobic tails aggregated in the core and hydrophilic heads comprising the exterior, mimicking structural features of biological membranes. This behavior makes micelles excellent tools for studying the complexity of membrane-drug interactions. A drug's therapeutic efficacy may be affected by the extent to which it binds to or solubilizes in pseudo-phase structures (i.e., micelles, membranes, or plasma proteins). The fraction of drug that is unbound and therefore able to diffuse into tissues and cross membranes is often very low when compared to the drug's total concentration. Differences observed in a drug's efficacy and toxicity, at similar total concentration levels, are often attributable to disparities in the drug's unbound fraction. The interactions of NSAIDs with cationic membrane mimics have been investigated using experimental methods for indomethacin with dihexadecyldimethylammonium bromide [8]; for piroxicam, meloxicam, and tenoxicam with cetyltrimethylammonium bromide (CTAB) [9]; and for diclofenac with small unilamellar vesicles [10]. The interactions of NSAIDs with lipid membranes have also been studied by molecular dynamics simulations [11].

In addition to serving as good mimics of biological membranes, surfactant micelles are also used as delivery vehicles for sparingly water-soluble drugs. Such drugs can partition into the hydrophobic interior of micelles, or may, in the case of oppositely charged surfactants, also electrostatically bind to the exterior of micelles. Advantages of surfactant micelles as delivery vehicles include their ability to: increase the drug's bioavailability; maintain a sustained release; and, protect drugs from degradation and metabolization [12]. The use of surfactant micelles as NSAID carries has been investigated using ibuprofen in anionic micelles [13]; naproxen and diclofenac in cationic micelles [14]; indomethacin in both anionic and cationic micellar assemblies [7]; and ibuprofen in amphiphilic polymers [2]. 
The partitioning of drugs into surfactant micelles can also be exploited through MEUF, a separation technique that could be employed to remove NSAIDs for contaminated waters. The global environmental impact of NSAIDs has only recently been assessed [15] [16]. Indications are that even low levels, $\mu \mathrm{g} \cdot \mathrm{L}^{-1}$, of drugs like ketoprofen and diclofenac can have toxic effects on fish [17] and birds [18]. The MEUF process has been studied previously for the removal of various environmental contaminants, including haloacetates [19]; arsenic [20]; naphthenic acid [21]; chromium [22]; and nitrobenzene [23]. The efficiency of MEUF strategies is governed by the partitioning behavior of the target contaminants.

Micellar-water partition coefficients, which are also referenced as binding or solubilization constants, have been evaluated for many NSAIDs using a variety of techniques. Isothermal titration calorimetry (ITC) has been used to study the partitioning into surfactant micelles of diclofenac sodium [14]; of ibuprofen [13]; of indomethacin [7]; and of naproxen [24]. Other techniques that have been used to investigate partition coefficients for NSAIDs in surfactant-based systems include biopartitioning micellar chromatography [25], fluorescence anisotropy [26], and spectrophotometry [27]. A convenient expression for defining the partition coefficient, $K$, is provided in Equation (1), where $X_{\mathrm{NSAID} \text {,mic }}$ is the mole fraction of drug in the micelles and $c_{\text {NSAID,bulk }}$ is the molar concentration of unsolubilized NSAID in bulk aqueous solution.

$$
K=\frac{X_{\text {NSAID,mic }}}{C_{\text {NSAID,bulk }}}
$$

The right-hand side of Equation (1) is easily evaluated using semi-equilibrium dialysis (SED) [28]. In the SED method, a membrane separates two compartments and retains micelles and solubilized/bound solute species on one side, while allowing monomeric surfactant and unsolubilized solutes to be transferred. After a period of several hours a state of thermodynamic semi-equilibrium is achieved between unsolubilized solute on both sides of the membrane.

The SED technique has been used to investigate the partitioning of a variety of organic and inorganic solutes into micellar pseudophases [19]. Though not used extensively for the study of drug-micelle interactions, SED was employed to investigate the binding of sulfonamide antibiotics to CTAB micelles [31]. Advantages of SED compared to other methodologies include its relatively low cost and overall reliability. In addition, it is easy to design SED experiments to evaluate $K$ as a function of $X_{\mathrm{NSAID} \text {,mic, }}$ providing what are referred to as solubilization isotherms [32]. Such experiments often demonstrate that $K$ is not a constant, but instead varies with the amount of solubilizate load incorporated in micelles. In this study, partition coefficients for the NSAIDs flurbiprofen and ketoprofen (see Figure 1) into CTAB micelles have been determined using SED. In addition, the interactions of these NSAIDs with CTAB micelles were examined by ${ }^{1} \mathrm{H}$ NMR spectrometry and UV spectrophotometry. 


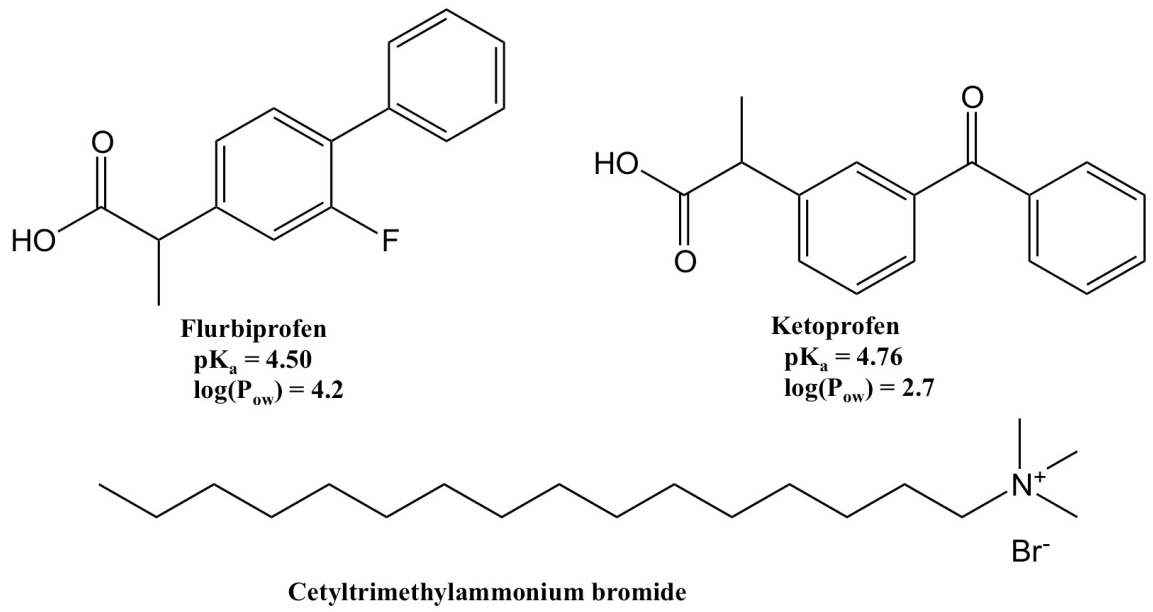

Figure 1. Physico-chemical properties NSAIDs and the surfactant studied [29] [30].

\section{Materials and Methods}

\subsection{Materials}

All materials utilized in this study were used as received from their respective manufacturers without further purification or modification. Solutions used for SED experiments contained phosphate buffered saline (PBS) prepared from 10X concentrate obtained from Sigma-Aldrich Chemicals. At the concentration used, 1X PBS contained $137 \mathrm{mM} \mathrm{NaCl}, 2.7 \mathrm{mM} \mathrm{KCl}, 10 \mathrm{mM} \mathrm{Na}_{2} \mathrm{HPO}_{4}$, and $1.8 \mathrm{mM}$ $\mathrm{KH}_{2} \mathrm{PO}_{4}$. Cetyltrimethylammonium bromide (CTAB, purity $\left.\geq 99 \%\right)$ was obtained from Acros Organics. The NSAIDs flurbiprofen and ketoprofen (purities $\geq 99 \%)$ were received from Sigma-Aldrich Chemicals. Analytical reagent grade chloroform and ACS reagent grade bromophenol blue were obtained from Fisher Chemical and Aldrich, respectively.

\subsection{SED Experiments}

The SED experiments used plexiglass Bel-Art Products dialysis cells, with $5 \mathrm{~mL}$ compartments separated by $6000 \mathrm{Da}$ MWCO regenerated cellulose membranes, also obtained from Bel-Art Products. Retentate compartments were filled with solutions containing $1 \times$ PBS, $10.0 \mathrm{mM} \mathrm{CTAB}$, and NSAID at concentrations in the range of $0.50-2.5 \mathrm{mM}$. Permeate compartments were filled with only $1 \times$ PBS. Cells were equilibrated for 24 hours in a Thelco Laboratory Precision Incubator maintained at $37^{\circ} \mathrm{C} \pm 1^{\circ} \mathrm{C}$. Studies performed in the absence of $\mathrm{CTAB}$ demonstrated that flurbiprofen and ketoprofen achieve an equilibrium state across the membrane within 15 - 20 hours and that inherit membrane-effects did not contribute to NSAID retention (see Figure 2). As described previously [19], the masses of permeate and retentate solutions were determined both when initially filled and when emptied. After the equilibration period, the concentration of NSAID in both compartments was determined. The concentration of CTAB in the permeate was also evaluated. 


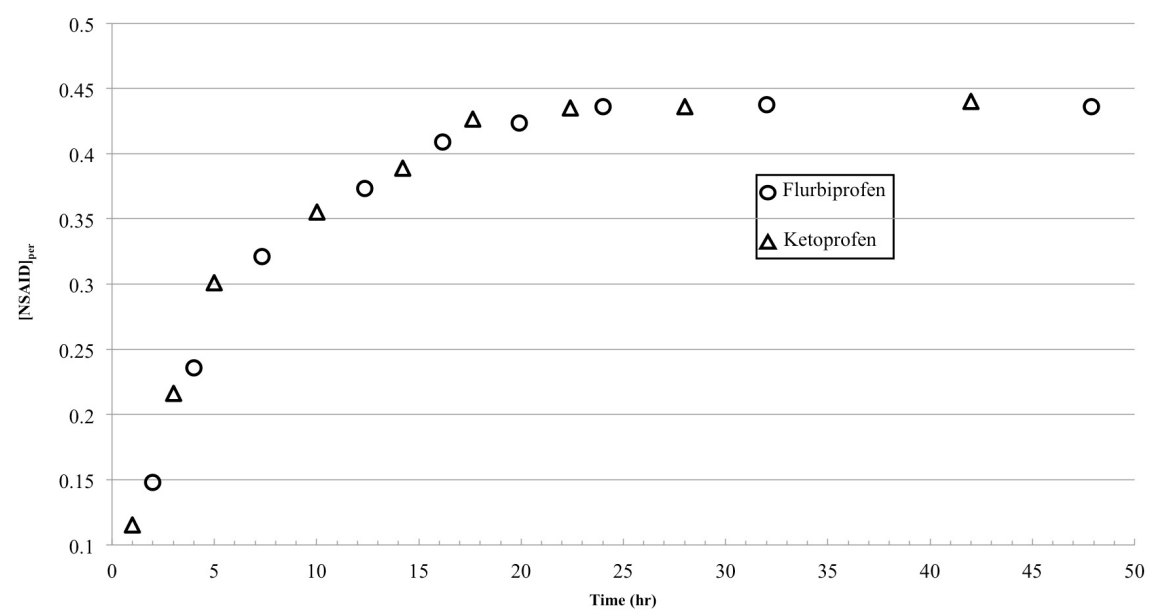

Figure 2. NSAID transfer from retentate to permeate.

\subsection{Analytical Methods}

Concentrations of the NSAIDs were determined by UV absorption, using an Agilent 8453 spectrophotometer, at their respective $\lambda_{\max }$ values under given solution conditions; in 1X PBS these were $247 \mathrm{~nm}$ and $261 \mathrm{~nm}$ for flurbiprofen for ketoprofen. The concentration of CTAB after equilibration in retentate and permeate was matched in standard solutions used for their respective analyses, necessitating separate calibration curves for permeate and retentate. A $1 \mathrm{~cm}$ pathlength was used for all absorption measurements, and analytes were diluted with appropriate $\mathrm{CTAB}$ solutions as necessary to obtain absorbance values in the range 0.1 to 1 .

Concentrations of CTAB in analyte solutions were determined using a methodology adapted from Adura et al. [33]. Briefly, to a $1 \mathrm{~mL}$ aliquot of analyte, 5 $\mathrm{mL}$ of $\mathrm{CHCl}_{3}$ and $1 \mathrm{~mL}$ of bromophenol blue solution were added in a $16 \times 150$ $\mathrm{mm}$ glass test-tube. The resulting mixture was then vortexed for 30 minutes. Next, the test-tubes were placed upright for 10 minutes. The organic layer was then removed using a Pasteur pipet and analyzed using an Agilent 8453 spectrophotometer, equipped with a $1 \mathrm{~cm}$ pathlength cuvette, at $606 \mathrm{~nm}$.

All ${ }^{1} \mathrm{H}$ NMR experiments were performed on a Bruker Ascend 300 spectrometer operating at $300.13 \mathrm{MHz}$. Temperature was maintained at $37.0^{\circ} \mathrm{C} \pm$ $0.1^{\circ} \mathrm{C}$ with a Bruker Smart Variable Temperature system using preconditioned compressed air. Spectra were generated from 16 scans at an acquisition time of $5.45 \mathrm{~s}$.

\subsection{Evaluation of $K$ and $X_{\mathrm{NSAID}, \mathrm{mic}}$}

The critical micelle concentration (CMC) for CTAB in 1X PBS used in this study was $0.11 \mathrm{mM}$, the concentration of surfactant in the permeate after the equilibration period. Figure 3 demonstrates the validity of this methodology, depicting both the concentrations of surfactant vs. time obtained in this study and literature $\mathrm{CMC}$ values obtained under similar experimental conditions (i.e., 1.0 


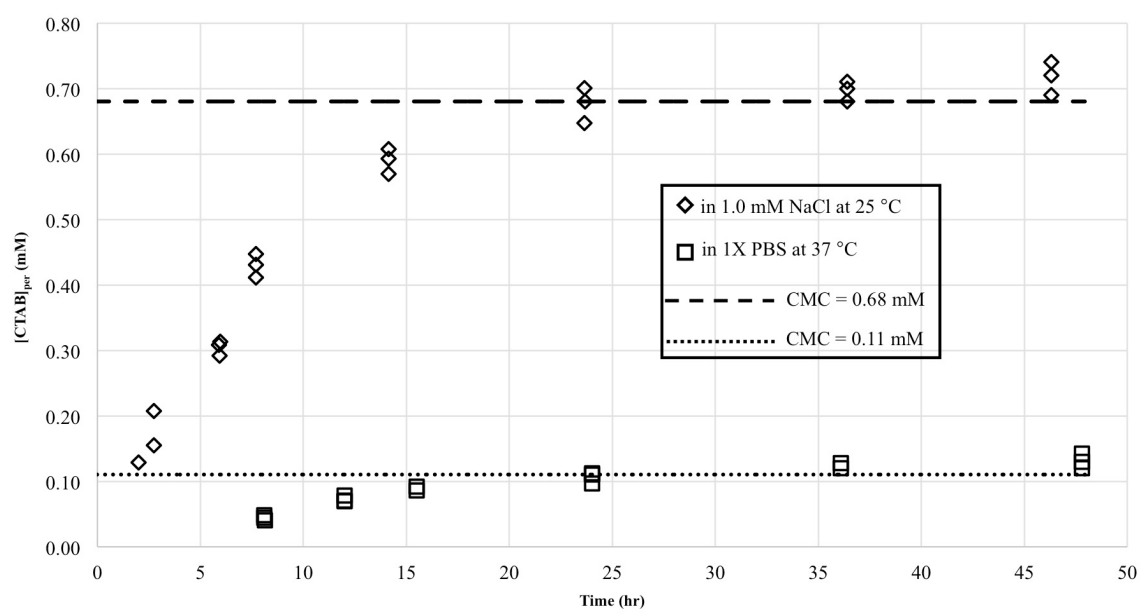

Figure 3. CTAB transfer from retentate to permeate.

$\mathrm{mM} \mathrm{NaCl}$ at $25^{\circ} \mathrm{C}$ [34]). The concentration of CTAB in the retentate after equilibration, $[C T A B]_{\text {ret }}$, was calculated from the initial amount of $C T A B$ placed in the retentate and the amount transferred to the permeate, assumed to be product of the CMC and final volume of the permeate. The concentration of CTAB in micelles, $[\mathrm{CTAB}]_{\text {mic }}$, was then determined as the difference between $[\mathrm{CTAB}]_{\mathrm{ret}}$ and CMC.

A typical assumption of the SED method is that the activities of unsolubilized solutes are equal in retentate and permeate. Given the use of 1X PBS in both compartments throughout this study, thus maintaining similar ionic strength conditions, it was reasonable to equate the concentrations of bulk NSAID in permeate ([NSAID $\left.]_{\text {bulk,per }}\right)$ and retentate ([NSAID $]_{\text {bulk,ret }}$ ). Since the equilibration period ended before appreciable micelles have formed in the permeate, the total concentration of NSAID in the permeate is simply [NSAID] bulk,per. The retentate concentration of NSAID in micelles, [NSAID] $]_{\text {mic }}$, was then calculated as the difference between total NSAID in the retentate ([NSAID $\left.]_{\text {ret }}\right)$ and [NSAID $]_{\text {bulk,per. }}$. Finally, $X_{\mathrm{NSAID} \text {,mic }}$ and $K$ were calculated using Equations (2) and (3), respectively.

$$
\begin{gathered}
X_{\mathrm{NSAID}, \mathrm{mic}}=\frac{[\mathrm{NSAID}]_{\mathrm{mic}}}{[\mathrm{NSAID}]_{\mathrm{mic}}+[\mathrm{CTAB}]_{\mathrm{mic}}} \\
K=\frac{X_{\text {NSAID,mic }}}{[\mathrm{NSAID}]_{\text {bulk,per }}}=\frac{X_{\mathrm{NSAID}, \mathrm{mic}}}{c_{\mathrm{NSAID}, \text { bulk }}}
\end{gathered}
$$

\section{Results \& Discussion}

\subsection{Solubilization Constants from SED}

The partitioning results for flurbiprofen and ketoprofen are provided in Figure 4. For both NSAIDs, $K$ is observed to decrease, almost linearly, with increasing $X_{\text {NSAID,mic. }}$ Across similar micellar mole fraction ranges, this trend has been observed for cresols with cetylpyridinium chloride (CPC) [35], for benzoate with CPC [36], and for phenol with CPC [37]. Dougherty and Berg [38] indicate that 
this linear relationship between $K$ and $X_{\text {NSAID,mic }}$ suggests a Langmuir-type adsorption at cationic micellar surfaces.

In several studies utilizing the SED method to investigate the partitioning of polar solubilites in ionic micelles, an expression like that provided in Equation (4) has been shown to well represent the dependence of the solubilization constant on micellar composition for $X_{\mathrm{NSAID} \text {,mic }}$ values less than 0.2 or 0.3 . In Equation (4), $K_{0}$ is the value of the of the solubilization constant in the limit as $X_{\mathrm{NSAID}, \mathrm{mic}}$ approaches zero and $B$ is obtained from the negative slope of the plot $K$ vs $X_{\mathrm{NSAID} \text {,mic }}$ divided by $K_{0}$. The $B$ parameter is an empirical constant that can be related to constants in the Langmuir adsorption equation [28] [39]. Values obtained for $K_{0}$ and $B$ using the SED method, from this and previous studies are provided in Table 1 .

$$
K=K_{0}\left(1-B X_{\text {NSAID,mic }}\right)
$$

Table 1. Micellar solubilization parameters for a variety of compounds.

\begin{tabular}{ccccc}
\hline Compound & Surfactant & $\boldsymbol{K}_{\mathbf{0}}$ & B & Reference \\
\hline Flurbiprofen & CTAB & 11,200 & 2.58 & This study \\
Ketoprofen & CTAB & 1950 & 3.04 & This study \\
Phenol & CPC & 81 & 1.09 & {$[39]$} \\
$p$-bromophenol & CPC & 833 & 1.20 & {$[41]$} \\
$p$-chlorophenol & CPC & 786 & 1.25 & {$[39]$} \\
2,4 -dichlorophenol & CPC & 2986 & 1.38 & {$[39]$} \\
Benzoic acid & CPC & 72 & 1.331 & {$[42]$} \\
$p$-cresol & CPC & 195 & 1.49 & {$[35]$} \\
\hline
\end{tabular}

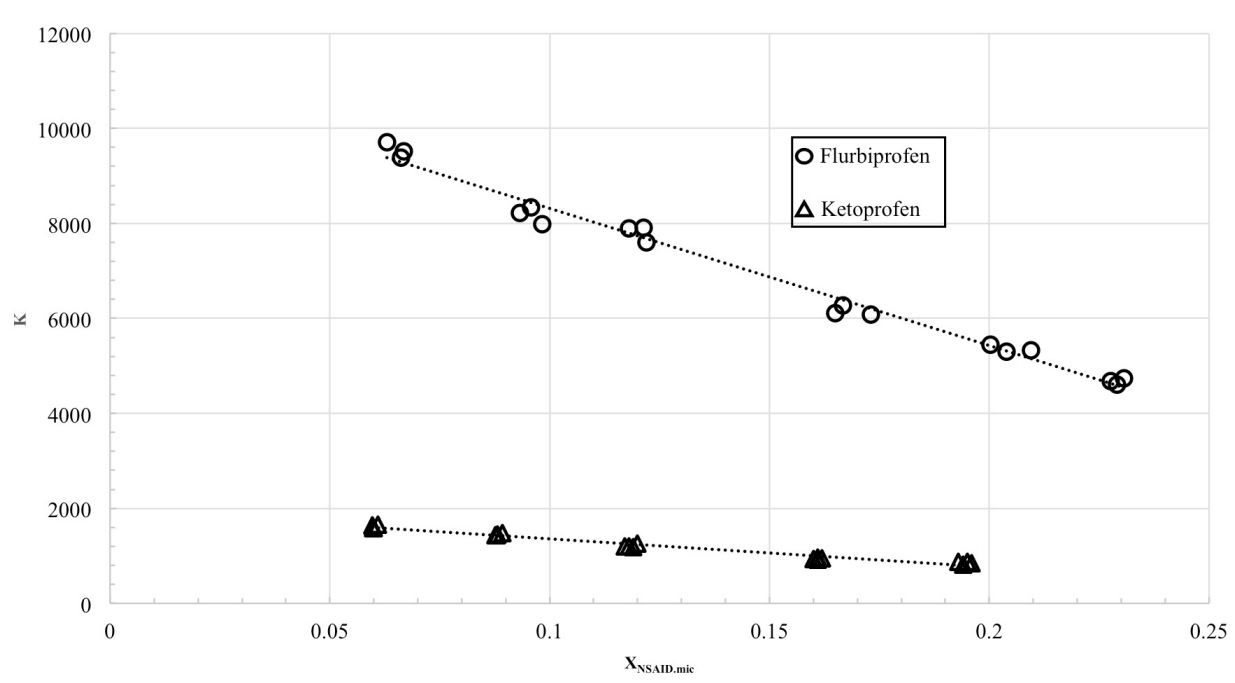

Figure 4. Dependence of NSAID partitioning into CTAB micelles on intramicellar mole fraction of drug. 
The pKa values obtained at $0.1 \mathrm{M}$ ionic strength in aqueous solution for flurbiprofen and ketoprofen are 4.50 [29] and 4.76 [30], respectively. While deprotonation constants are known to vary with surfactant concentration [40], in the case of cationic surfactants apparent $\mathrm{pKa}$ values decrease with increasing micelle concentration. Deprotonated forms dominate the speciation for both flurbiprofen and ketoprofen in 1× PBS and electrostatic attraction between negatively charged NSAIDs and cationic micelles certainly contributes to the extent of partitioning and the relatively large $K$ and $K_{0}$ values. For comparison, $K_{0}\left(c^{\circ}=1 \mathrm{M}\right)$ values of 833 and 786 were obtained for the neutral molecules $p$-bromophenol and $p$-chlorophenol in CPC micelles, respectively [41]. The larger $K_{0}$ for flurbiprofen compared to ketoprofen correlates with their respective octanol-water partition coefficients, provided in Figure 1, reflecting its greater lipophilicity.

\subsection{Locus of Solubilization}

Variations in the wavelength of maximum absorption, $\lambda_{\max }$, for flurbiprofen and ketoprofen as functions of CTAB concentration in aqueous solution at $37^{\circ} \mathrm{C}$ are presented in Figure 5. For flurbiprofen, a bathochromic shift from $247 \mathrm{~nm}$ to $252 \mathrm{~nm}$ was observed. This red shift is attributable to hydrophobic interactions between $\pi$-electrons in the drug and alkyl tails of the surfactants, indicating that, for flurbiprofen, the locus of solubilization is more in the micellar interior. Similar solubilization and corresponding electronic spectral behavior has been observed previously for crystal violet in CTAB micelles [43]. For ketoprofen, a slight hypsochromic shift from $260 \mathrm{~nm}$ to $257 \mathrm{~nm}$ was observed and indicates that electrostatic attraction between the drug's carboxylate group and the cationic micellar exterior plays a more significant role in partitioning. The locus of solubilization for ketoprofen is likely more towards the charged exterior of $\mathrm{CTAB}$ micelles, in the Stern layer. Interactions between methyl orange and dodecyltrimethylammonium bromide (DTAB) micelles display similar blue-shifted spectra and were attributed to incorporation of dye molecules into the shell of DTAB micelles [44]. Further insights into the locus of solubilization are depicted in Figure 6. A greater upfield shift of the proton on the $\alpha$-carbon of flurbiprofen, about $0.29 \mathrm{ppm}$, was seen when compared to the proton on the $\alpha$-carbon of ketoprofen, about $0.09 \mathrm{ppm}$. Large upfield shifts were observed by Vermathen et al. [45] for fluoro-substituted benzoates in tetradecyltrimethylammonium micelles and were attributed to proton location deeper inside the micellar palisade layer.

In addition to use in probing loci of solubilization, NMR techniques have also been employed to determine micellar solubilization constants [46]. In the future, both SED and NMR techniques will be used to investigate the partitioning of other NSAIDs into surfactant micelles, e.g., diclofenac, meclofenamic acid, diflunisal. Of particular interest will be the establishment of a methodology whereby NMR data can be used to assess solubilization constants as a function of micellar composition. 


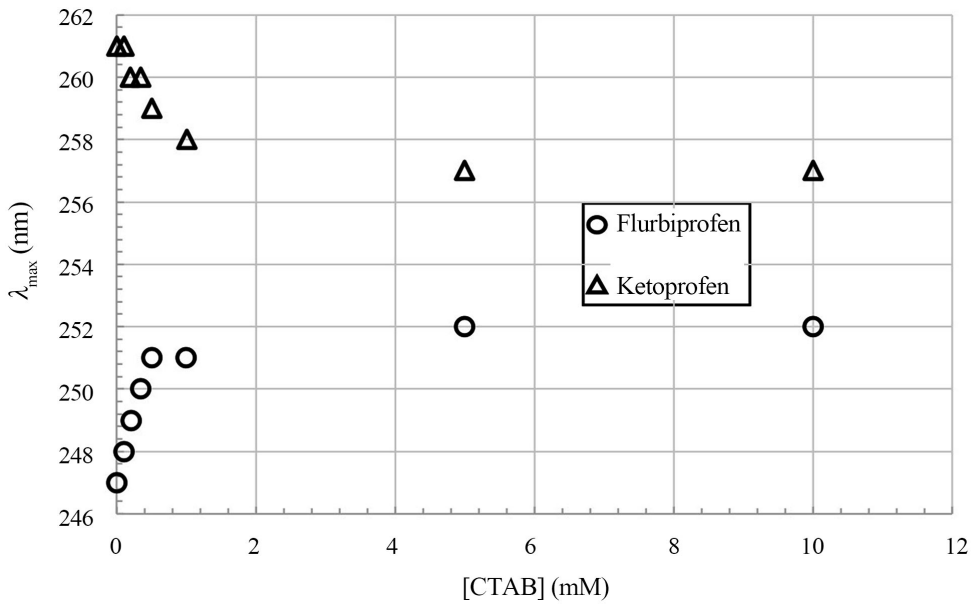

Figure 5. Variation of absorption maxima for NSAIDs as a function of [CTAB].
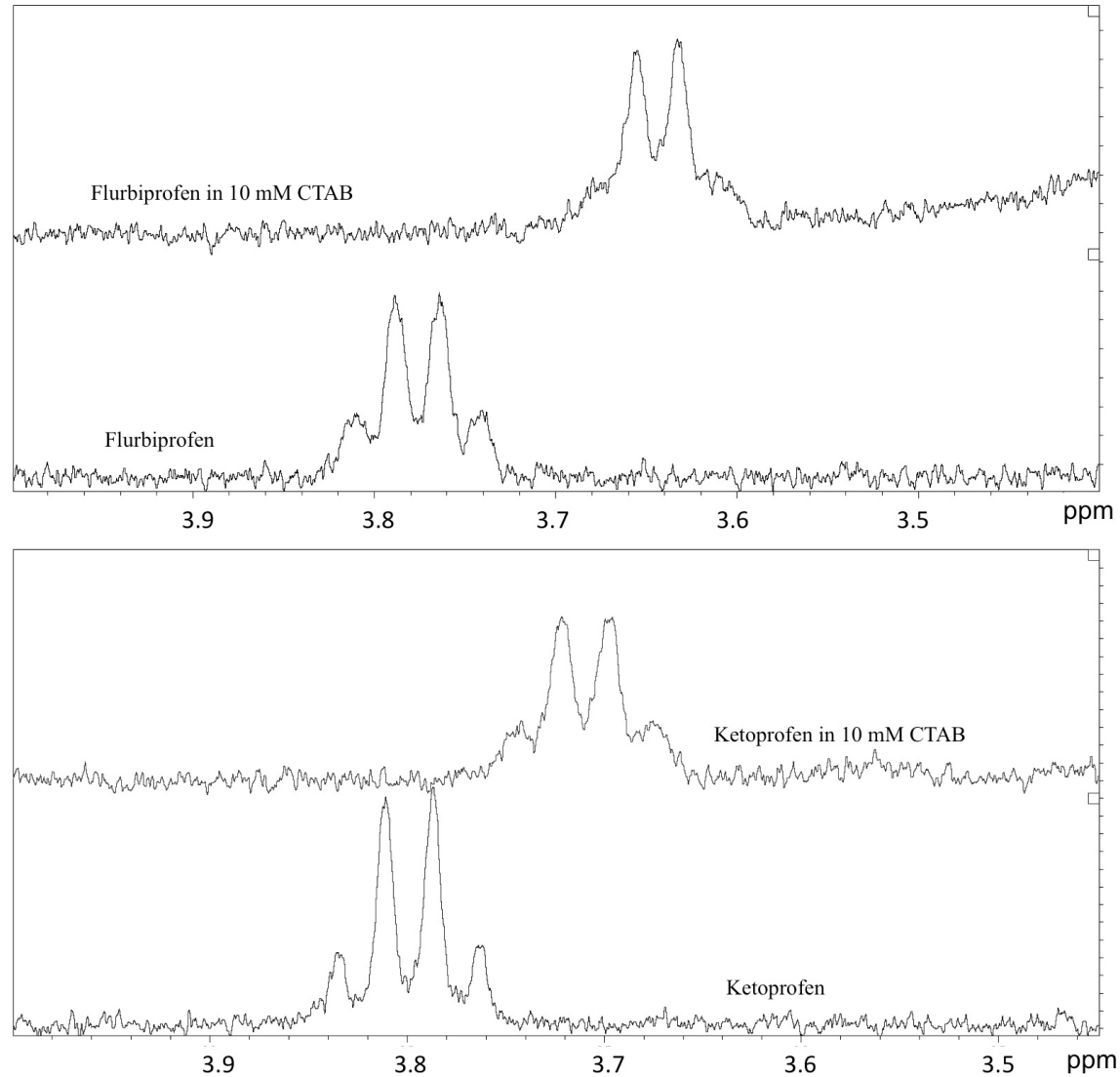

Figure 6. ${ }^{1} \mathrm{H}-\mathrm{NMR}$ spectra of proton on $\alpha$-carbons of the NSAIDs in the presence and absence of CTAB.

\section{Conclusion}

Semi-equilibrium dialysis was used to assess the partitioning of flurbiprofen and ketoprofen into CTAB micelles. The results were well correlated by the expression $K=K_{0}\left(1-B X_{\mathrm{NSAID}, \mathrm{mic}}\right)$, with $K_{0}$ being larger for flurbiprofen than ketoprofen. A hypsochromic shift in the UV spectrum of ketoprofen indicates its lo- 
cus of solubilization is in the Stern layer of CTAB micelles, while the bathochromic shift in the spectrum of flurbiprofen suggests solubilization further into the micellar interior. These loci of solubilization were further supported by differences in chemical shifts in the ${ }^{1} \mathrm{H}-\mathrm{NMR}$ spectra of both NSAIDs in the presence and absence of CTAB micelles. The extent of partitioning of both drugs into $\mathrm{CTAB}$ micelles suggests that MEUF separations are feasible for their removal from contaminated marine systems.

\section{Acknowledgements}

This publication was made possible by a grant from Weill Cornell MedicineQatar under its Student Research Mentorship Program award number SRMP $02-\mathrm{ROACH}$. Its contents are solely the responsibility of the authors and do not necessarily represent the official views of the Weill Cornell Medicine-Qatar.

\section{Conflicts of Interest}

The authors declare no conflicts of interest regarding the publication of this paper.

\section{References}

[1] Gargiulo, G., Capodanno, D., Longo, G., Capranzano, P. and Tamburino, C. (2014) Updates on NSAIDS in Patients with and without Coronary Artery Disease: Pitfalls, Interactions, and Cardiovascular Outcomes. Expert Review of Cardiovascular Therapy, 12, 1185-1203. https://doi.org/10.1586/14779072.2014.964687

[2] Marques, J.G., Gaspar, V.M. and Costa, E. (2014) Synthesis and Characterization of Micelles as Carriers of Non-steroidal Anti-Inflammatory Drugs (NSAIDs) for Application in Breast Cancer Therapy. Colloids and Surfaces B: Biointerfaces, 113, 375-383. https://doi.org/10.1016/j.colsurfb.2013.09.037

[3] Iwana, T. (2009) NSAIDs and Colorectal Cancer Prevention. Journal of Gastroenterology, 44, 72-76. https://doi.org/10.1007/s00535-008-2265-7

[4] Bell, N.H., Hollis, B.W., Shary, J.R., Eyre, D.R., Eastell, R., Colwell, A. and Russell, G.G. (1994) Diclofenac Sodium Inhibits Bone Resorption in Postmenopausal Women. American Journal of Medicine, 96, 349-353.

https://doi.org/10.1016/0002-9343(94)90065-5

[5] Sheha, M. (2012) Pharmacokinetic and Ulcerogenic Studies of Naproxen Prodrugs Designed for Specific Brain Delivery. Archives of Pharmacalal Research, 35, 523-530. https://doi.org/10.1007/s12272-012-0316-3

[6] Kalepu, S. and Nekkanti, V. (2015) Insoluble Drug Delivery Strategies: Review of Recent Advances and Business Prospects. Acta Pharmaceutica Sinica B, 5, 442-453. https://doi.org/10.1016/j.apsb.2015.07.003

[7] Maity, B., Chatterjee, A., Ahmed, S.A. and Seth, D. (2015) Interaction of Nonsteroidal Anti-Inflammatory Drug Indomethacin with Micelles and Its Release. The Journal of Physical Chemistry B, 119, 3776-3785.

https://doi.org/10.1021/acs.jpcb.5b00467

[8] Koirala, S., Roy, B., Guha, P., Bhattarai, R., Sapkota, M., Nahak, P., Karmakar, G., Mandal, A.K., Kumar, A. and Panda, A.K. (2016) Effect of Double Tailed Cationic Surfactants on the Physicochemical Behavior of Hybrid Vesicles. RSC Advances, 6, 
13786-13796. https://doi.org/10.1039/C5RA17774J

[9] Chakraborty, H., Banerjee, R. and Sarkar, M. (2003) Incorporation of NSAIDs in Micelles: Implication of Structural Switchover in Drug-Membrane Interactions. Biophysical Chemistry, 104, 315-325. https://doi.org/10.1016/S0301-4622(02)00389-7

[10] Balon, K., Riebesehl, B.U. and Muller, B.W. (1999) Determination of Liposome Partitioning of Ionizable Drugs by Titration. Journal of Pharmaceutical Sciences, 88, 802-806. https://doi.org/10.1021/js9804213

[11] Boggara, M.B. and Krishbanoorti, R. (2010) Partitioning of Nonsteroidal Antiinflammatory Drugs in Lipid Membranes: A Molecular Dynamics Simulation Study. Biophysical Journal, 98, 586-595. https://doi.org/10.1016/j.bpj.2009.10.046

[12] Croy, S.R. and Kwon, G.S. (2006) Polymeric Micelles for Drug Delivery. Current Pharmaceutical Design, 12, 4669-4684. https://doi.org/10.2174/138161206779026245

[13] Dey, A., Sandre, V., Marangoni, D.G. and Ghosh, S. (2018) Interaction between a Nonsteroidal Anti-Inflammatory Drug (Ibuprofen) and an Anionic Surfactant (AOT) and Effects of Salt (NaI) and Hydrotrope (4-4-4). The Journal of Physical Chemistry $B, 122,3974-3987$. https://doi.org/10.1021/acs.jpcb.8b00687

[14] Talele, P., Choudhary, S. and Kishore, N. (2016) Understanding Thermodynamics of Drug Partitioning in Micelles and Delivery to Proteins: Studies with Naproxen, Diclofenac Sodium, Tetradecyltrimethylammonium Bromide, and Serum Albumin. The Journal of Chemical Thermodynamics, 92, 182-190. https://doi.org/10.1016/j.jct.2015.09.015

[15] Rocca, L.M., Gentili, A., Caretti, F., Curini, R. and Perez-Fernandez, V. (2015) Occurrence of Non-Steroidal Anti-Inflammatory Drugs in Surface Water of Central Italy by Liquid Chromatography-Tandem Mass Spectroscopy. International Journal Environmental Analytical Chemistry, 95, 685-697. https://doi.org/10.1080/03067319.2015.1046059

[16] Lolic, A., Paiga, P., Santos, L.H., Ramos, S., Correia, M. and Delerue-Matos, C. (2015) Assessment of Non-Steroidal Anti-Inflammatory and Analgesic Pharmaceuticals in Seawaters of North Portugal: Occurrence and Environmental Risks. Science of the Total Environment, 508, 240-250. https://doi.org/10.1016/j.scitotenv.2014.11.097

[17] Diniz, M.S., Salgado, R., Pereira, V.J., Carvalho, G., Oehmen, A., Reis, M.A.M. and Noronha, J.P. (2015) Ecotoxicity of Ketoprofen, Diclofenac, Atenolol and Their Photolysis Byproducts in Zebrafish (Danio rerio). Science of the Total Environment, 505, 282-289. https://doi.org/10.1016/j.scitotenv.2014.09.103

[18] Oaks, J.L., Gilbert, M., Virani, M.Z., Watson, R.T., Meteyer, C.U., Rideout, B.A., Shivapradad, H.L., Ahmed, S., Chaudry, M.J.I, Arshad, M., Mahmood, S., Ali, A. and Khan, A.A. (2004) Diclofenac Residues as the Cause of Vulture Population Decline in Pakistan. Nature, 427, 630-633. https://doi.org/10.1038/nature02317

[19] Roach, J.D., Premjee, M.M., Buddhavarapu, S. and Hassib, A. (2013) A Study of the Partitioning of Haloacetates into Cetylpyridinium Chloride Micelles Using Semiequilibrium Dialysis and Ultrafiltration. Journal of Colloid and Interface Science, 394, 293-300. https://doi.org/10.1016/j.jcis.2012.11.065

[20] Iqbal, J., Kim, H.-J., Yang, J.-S., Baek, K. and Yang, J.-W. (2007) Removal of Arsenic from Groundwater by Micellar-Enhanced Ultrafiltration (MEUF). Chemosphere, 66, 970-976. https://doi.org/10.1016/j.chemosphere.2006.06.005

[21] Deriszadeh, A., Harding, T.G. and Husein, M.M. (2009) Improved MEUF Removal of Naphthenic Acids from Produced Water. Journal of Membrane Science, 32, 
161-167. https://doi.org/10.1016/j.memsci.2008.09.047

[22] Juang, R.-S., Xu, Y.-Y. and Chen, C.-L. (2003) Separation and Removal of Metal Ions from Dilute Solutions Using Micellar-Enhanced Ultrafiltration. Journal of Membrane Science, 218, 257-267. https://doi.org/10.1016/S0376-7388(03)00183-2

[23] Bielska, M. and Szymanowski, J. (2004) Micellar Enhanced Utrafiltration of Nitrobenzene and 4-Nitrophenol. Journal of Membrane Science, 243, 273-281. https://doi.org/10.1016/j.memsci.2004.06.030

[24] Mukhija, A. and Kishore, N. (2018) Drug Partitioning in Individual and Mixed Micelles and Interactions with Protein upon Delivery from Micellar Media. Journal of Molecular Liquids, 265, 1-15. https://doi.org/10.1016/j.molliq.2018.05.107

[25] Cudina, O., Markovic, B., Karljikovic-Ranjic, K. and Vladimirov, S. (2012) Biopartitioning Micellar Chromatography-Partition Coefficient Micelle/Water as a Potential Descriptor for Hydrophobicity in Prediction of Oral Drug Absorption. Analytical Letters, 45, 677-688. https://doi.org/10.1080/00032719.2011.653904

[26] Chakraborty, H., Roy, S. and Sarkar, M. (2005) Interaction of Oxicam NSAIDs with DMPC Vesicles: Differential Partitioning of Drugs. Chemistry and Physics of Lipids, 138, 20-28. https://doi.org/10.1016/j.chemphyslip.2005.07.005

[27] Ullah, I., Baloch, M.K., Ullah, I. and Mustaqeem, M. (2014) Enhancement in Aqueous Solubility of Mefenamic Acid Using Micellar Solutions of Various Surfactants. Journal of Solution Chemistry, 43, 1360-1373. https://doi.org/10.1007/s10953-014-0217-9

[28] Christian, S.D., Tucker, E.E., Scamehorn, J.F. and Uchiyama, H. (1994) On the Interpretation of Solubilization Results Obtained from Semi-Equilibrium Dialysis Experiments. Colloid and Polymer Science, 271, 745-754. https://doi.org/10.1007/BF00659289

[29] Domanska, U., Pobudkowska, A., Pelczarska, A. and Gierycz, P. (2009) pKa and Solubility of Drugs in Water, Ethanol, and 1-Octanol. The Journal of Physical Chemistry $B, 113,8941-8947$. https://doi.org/10.1021/jp900468w

[30] Sheng, J.J., Kasim, N.A., Chandrasekharan, R. and Amidon, G.L. (2006) Solubilization and Dissolution of Insoluble Weak Acid, Ketoprofen: Effects of $\mathrm{pH}$ Combined with Surfactant. European Journal of Pharmaceutical Sciences, 29, 306-314. https://doi.org/10.1016/j.ejps.2006.06.006

[31] Sarker, A.K., Cashin, P.J., Balakrishnan, V.K., Exall, K., Chung, H.K., Buncel, E. and Brown, R.S. (2016) Determining Binding of Sulfonamide Antibiotics to CTABr Micelles Using Semi-Equilibrium Dialysis. Separation and Purification Technology, 162, 134-141. https://doi.org/10.1016/j.seppur.2016.02.021

[32] Gadelle, F., Koros, W.J. and Schiechter, R.S. (1995) Solubilization Isotherms of Aromatic Solutes in Surfactant Aggregates. Journal of Colloid and Interface Science, 170, 57-64. https://doi.org/10.1006/jcis.1995.1071

[33] Adura, C., Guzman, F., Alvarez-Lueje, A. and Kogan, M. (2014) Ion-Pair Method to Determine the CTAB Content in Gold Nanorods Samples. Journal of the Chilean Chemical Society, 59, 2701-2704. https://doi.org/10.4067/S0717-97072014000400015

[34] Zhang, C., Geng, T., Jiang, Y., Zhao, L., Ju, H. and Wang, Y. (2017) Impact of NaCl Concentration on Equilibrium and Dynamic Surface Adsorption of Cationic Surfactants in Aqueous Solution. Journal of Molecular Liquids, 238, 423-429. https://doi.org/10.1016/j.molliq.2017.05.033

[35] Bhat, S.N., Smith, G.A., Tucker, E.E., Christian, S.D. and Scamehorn, J.F. (1987) Solubilization of Cresols by 1-Hexadecylpyridinium Chloride Micelles and Removal of Cresols from Aqueous Solution by Micellar-Enhanced Ultrafiltration. Industrial 
and Engineering Chemistry Research, 26, 1217-1222. https://doi.org/10.1021/ie00066a026

[36] Mahmoud, F.Z., Christian, S.D., Tucker, E.E., Taha, A.A. and Scamehorn, J.F. (1989) Semiequilibrium Dialysis Study of the Solubilization of Benzoate Anion by Aqueous Hexadecylpyridinium Chloride. The Journal of Physical Chemistry, 93, 5903-5906. https://doi.org/10.1021/j100352a050

[37] Uchiyama, H., Christian, S.D., Tucker, E.E. and Scamehorn, J.F. (1993) A Modified Semiequilibrium Dialysis Method for Studying Solubilization in Surfactant Micelles: Testing the Semiequilibrium Assumption. The Journal of Physical Chemistry, 97, 10868-10871. https://doi.org/10.1021/j100143a056

[38] Dougherty, S.J. and Berg, J.C. (1974) Distribution Equilibria in Micellar Solutions. Journal of Colloid and Interface Science, 48, 110-121. https://doi.org/10.1016/0021-9797(74)90333-6

[39] Lee, B.-H., Christian, S.D., Tucker, E.E. and Scamehorn, J.F. (1990) Solubilization of Mono- and Dichlorophenols by Hexadecylpyridinium Chloride Micelles. Effects of Substituent Groups. Langmuir, 6, 230-235. https://doi.org/10.1021/la00091a037

[40] Loh, W. and Volpe, L.O. (1992) Interactio of Alkyl p-Hydroxybenzoates with Micelles: Evaluation of the Partition Coefficients and Ionization Constants. Journal of Colloid Interface Science, 154, 369-377. https://doi.org/10.1016/0021-9797(92)90151-B

[41] Lee, B.H., Christian, S.D., Tucker, E.E. and Scamehorn, J.F. (1991) Substituent Group Effects on the Solubilization of Polar Aromatic Solutes (Phenols, Anilines, and Benzaldehydes) by $\mathrm{N}$-Hexadecylpyridinium Chloride. The Journal of Physical Chemistry, 95, 360-365. https://doi.org/10.1021/j100154a065

[42] Higazy, W.S., Mahmoud, F.Z., Taha, A.A. and Christian, S.D. (1988) Effects on the Micellar Solubilization of Organic Compounds by Surfactant Micelles. I. Length of Carboxylic Side Chains in Aromatic Acids. Journal of Solution Chemistry, 17, 191-202. https://doi.org/10.1007/BF00646173

[43] Ghosh, A., Mondal, S., Das, S. and Biswas, R. (2012) Spectroscopic Investigation of Interaction between Crystal Violet and Various Surfactants (Cationic, Anionic, and Gemini) in Aqueous Solution. Fluid Phase Equilibria, 332, 1-6. https://doi.org/10.1016/j.fluid.2012.06.019

[44] Petcu, A.R., Rogozea, E.A., Lazar, C.A., Olteanu, N.L., Meghea, A. and Mihaly, M. (2016) Specific Interactions with Micelle Micoenvironment in Different Charged Dye/Surfactant Systems. Arabian Journal of Chemistry, 9, 9-17. https://doi.org/10.1016/j.arabjc.2015.09.009

[45] Vermathen, M., Stiles, P., Bachofer, S.J. and Simonis, U. (2002) Investigations of Monofluoro Substituted Benzoates at the Tetradecyltriethylammonium Micellar Interface. Langmuir, 18, 1030-1042. https://doi.org/10.1021/la0109765

[46] Fielding, L. (2000) Determination of Association Constants $\left(K_{a}\right)$ from Solution NMR Data. Tetrahedron, 56, 6151-6170. https://doi.org/10.1016/S0040-4020(00)00492-0 